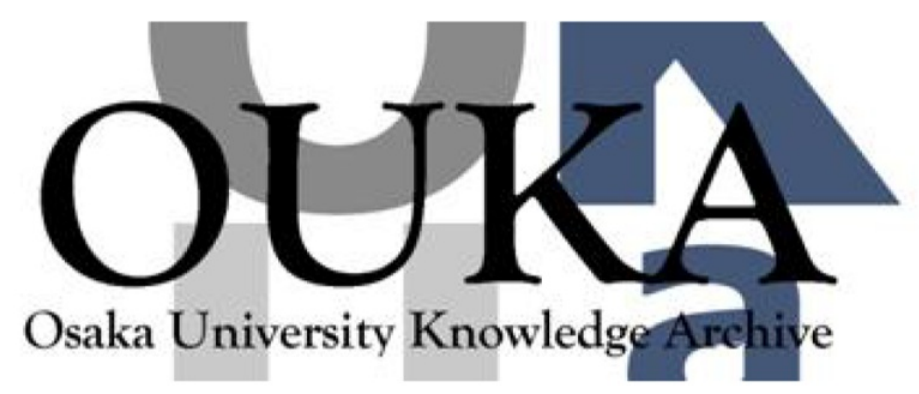

\begin{tabular}{|c|l|}
\hline Title & $\begin{array}{l}\text { Equation-of-state measurements for polystyrene } \\
\text { at multi-TPa pressures in laser direct-drive } \\
\text { experiments }\end{array}$ \\
\hline Author(s) & Ozaki, N.; Ono, T.; Takamatsu, K. et al. \\
\hline Citation & $\begin{array}{l}\text { Physics of Plasmas. 12(12) p. 124503-1-p. 124503- } \\
4\end{array}$ \\
\hline Issue Date & $2005-12$ \\
\hline oaire:version & VoR \\
\hline URL & https://hdl. handle. net/11094/3285 \\
\hline rights & \\
\hline Note & \\
\hline
\end{tabular}

Osaka University Knowledge Archive : OUKA

https://ir. Library. osaka-u. ac. jp/

Osaka University 


\title{
Equation-of-state measurements for polystyrene at multi-TPa pressures in laser direct-drive experiments
}

\author{
N. Ozaki, ${ }^{\text {a) }}$ T. Ono, K. Takamatsu, and K. A. Tanaka \\ Institute of Laser Engineering, Osaka University, Suita, Osaka 565-0871, Japan \\ and Faculty of Engineering, Osaka University, Suita, Osaka 565-0871, Japan \\ M. Nakano and T. Kataoka \\ Faculty of Engineering, Osaka University, Suita, Osaka 565-0871, Japan \\ M. Yoshida and K. Wakabayashi \\ National Institute of Advanced Industrial Science and Technology, Tsukuba, Ibaraki 305-8565, Japan \\ M. Nakai, K. Nagai, K. Shigemori, and T. Yamanaka \\ Institute of Laser Engineering, Osaka University, Suita, Osaka 565-0871, Japan \\ K. Kondo \\ Materials and Structures Laboratory, Tokyo Institute of Technology, Yokohama, \\ Kanagawa 226-8503, Japan
}

(Received 6 September 2005; accepted 14 November 2005; published online 20 December 2005)

Equation-of-state (EOS) measurements for polystyrene in TPa (10 Mbar) pressure regions are presented. Polystyrene Hugoniot data were obtained up to $2.7 \mathrm{TPa}$ using impedance matching techniques with laser direct drive at the GEKKO/HIPER laser facility [N. Miyanaga et al., in Proceedings of the 18th International Conference on Fusion Energy (IAEA, Sorrento, Italy, 2001), IAEA-CN-77] The results were compared with theoretical models and previous experimental data and found to be in good agreement with the previous data obtained by different drive and diagnostic techniques. (C) 2005 American Institute of Physics. [DOI: 10.1063/1.2149310]

Equation-of-state (EOS) measurements of matter at conditions of extremely high pressure and temperature are of great interest in several fields of modern physics. ${ }^{1-3}$ In inertial fusion energy (IFE) research, for example, the compression process depends critically on EOS of the fuel capsule materials. ${ }^{3,4}$ In order to accurately predict and analyze the experimental results by numerical simulations, reliable EOS information is required. Hydrocarbon polymers (plastics) play important roles as the shell materials of the fuel capsule, because plastics meet the immediate requirements for the pellet shell: low density, smooth outer and inner surfaces, sphericity, and concentricity. Therefore, polystyrene (PS) has been used extensively in the basic experiments.

A planar single shock wave drives a sample material to a point on the principal Hugoniot curve of the material in EOS phase space from an initial state. In EOS experiments, two independent variables for the sample are simultaneously measured under the shock condition, which appear in the Rankine-Hugoniot conservation relations

$$
\begin{aligned}
& P-P_{0}=\rho_{0} U_{s} u_{p}, \\
& \rho / \rho_{0}=U_{s} /\left(U_{s}-u_{p}\right),
\end{aligned}
$$

and

\footnotetext{
${ }^{a)}$ Present address: Laboratoire pour l'Utilisation de Lasers Intenses (LULI), Ecole Polytechnique, 91128 Palaiseau Cedex, France. Electronic mail: norimasa.ozaki@polytechnique.fr
}

$$
E-E_{0}=\frac{1}{2}\left(P+P_{0}\right)\left(1 / \rho_{0}-1 / \rho\right)
$$

where $P, \rho, E, U_{s}$, and $u_{p}$ are pressure, density, internal energy behind shock front, shock velocity, and particle velocity, respectively. The zero subscripts denote the initial material condition ahead of the shock front. ${ }^{5}$

High-power lasers have extended the capability of EOS studies, providing TPa (10 Mbar) pressures, ${ }^{6-8,10,11,13}$ even for low- $Z$ materials such as plastics ${ }^{9,12}$ for which only theoretical model and calculation had been available. Cauble et al. independently measured three Hugoniot variables $\left(U_{s}\right.$, $u_{p}$, and $\rho / \rho_{0}$ ) of polystyrene up to 4 TPa using laser indirectdrive and $\mathrm{x}$-ray radiography diagnostic techniques. ${ }^{9}$

In this paper, laser direct-drive EOS experiments for polystyrene based on the most standard experimental technique, the impedance matching method (IMM), are described. Polystyrene Hugoniot data obtained by an experimental scheme completely different from the indirect-drive method are presented. The results are compared with theoretical models and the previous data.

A series of experiments was conducted on the HIPER (High Intensity Plasma Experimental Research) laser facility, ${ }^{14}$ which is an irradiation system of the GEKKO XII (GXII): Nd glass laser system at the Institute of Laser Engineering (ILE), Osaka University. ${ }^{15}$ The HIPER provides onedimensional compression by smoothed laser beams with short wavelength and high intensity. In the system, 12 beams of the GXII are bundled in an $F / 3$ cone angle. Nine of the 12 beams were used in this experiment. The wavelength is 
$351 \mathrm{~nm}(3 \omega)$, which is the third harmonics of a $1053 \mathrm{~nm}(\omega)$ fundamental. Temporal behavior of the laser pulse was approximately a square shape in time with a full width at half maximum (FWHM) of $2.5 \mathrm{~ns}$ and a rise and fall time of 100 ps. The focal-spot diameter was typically $600 \mu \mathrm{m}$. In the beams, smoothing by the spectral dispersion (SSD) technique $^{16}$ is applied, and also Kinoform phase plates (KPPs) (Ref. 17) are installed to obtain a uniform irradiation pattern. The planarity of the driven shock wave was better than $\pm 0.7 \%$ at the central region of over $200 \mu \mathrm{m}$ diameter. This value corresponds to a shock arrival time difference of $\pm 8 \mathrm{ps}$ at the rear surface of the planar target. The temporal steadiness of the shock was verified using wedged targets, typically estimated as $\pm 1.3 \%$ steady for $\sim 2 \mathrm{~ns} .{ }^{13}$ The spatial and temporal uniformities were sufficient for our EOS measurements.

The impedance matching method, which is the most conventional technique to determine Hugoniot, makes it possible to obtain an EOS point by only measuring two shock velocities in two materials: an EOS standard and an unknown sample. This method yields an EOS point of the sample material based on the EOS standard reference. ${ }^{5}$ In our IMM experiments, aluminum (Al) was used as EOS standard. We used two types of target bases differentiated by the material that is hit by the laser. The first is a plain Al base target for low laser intensity. The second is a two-layered base target with a $\mathrm{CH}$ (polystyrene) ablator to suppress thermal radiation preheating in high-intensity irradiation. The $\mathrm{CH}$ is overcoated with a thin Al layer of 1000 thickness on the laser side to prevent direct laser shine-through. Using a numerical code MY1DL based on a one-dimensional hydrodynamic Lagrangian scheme, ${ }^{18}$ we optimized the target thicknesses to maintain steady shock pressures under our laser conditions. The $\mathrm{Al}$ base thickness was typically between 40 and $70 \mu \mathrm{m}$. The $\mathrm{Al}$ step height was almost $20 \mu \mathrm{m}$, and the PS step ranged between 19 and $25 \mu \mathrm{m}$. The gap between both the steps was adjusted to be $50-100 \mu \mathrm{m}$. To fabricate step targets, an adhesion technique was used with a single molecular membrane coating. ${ }^{19}$ All targets were characterized by a confocal laser 2D scanning microscope with a minimum scale value in height of $10 \mathrm{~nm}$.

Self-emission from the target rear surface was measured with two visible streak camera systems coupled with a charge-coupled-device (CCD) camera. Another streak camera recorded reflection of a probe laser from the target. An injection-seeded Q-switched yttrium-aluminum-garnet (YAG) laser was used as the probe light. The maximum energy was $0.7 \mathrm{~J}$ at a wavelength of $532 \mathrm{~nm}$. These diagnostic systems were described in detail in Refs. 20 and 13.

Figure 1 shows a schematic diagram of the experimental setup and a typical streaked image obtained by the selfemission measurement. Time proceeds from the top to the bottom. The $\mathrm{Al}$ and PS step are on the left- and right-hand side, respectively. The time intervals, $\Delta t^{\mathrm{Al}}$ and $\Delta t^{\mathrm{PS}}$, correspond to the transit time of the shock wave propagating through each step, where superscripts denote the material. Since the step heights were known, the shock velocities could be calculated. For example, in the shot 25368 the
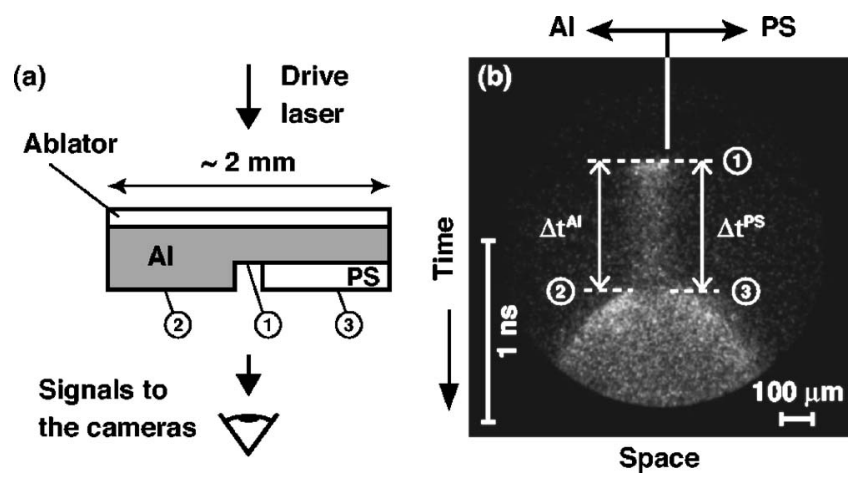

FIG. 1. (a) Schematic diagram of experimental setup. (b) Typical streaked image of self-emission measurement with double-step target. The time interval $\Delta t$ corresponds to the traveling time of the shock through each step.

shock velocity of Al, $U_{s}^{\mathrm{Al}}$, was $26.24 \pm 0.514 \mathrm{~km} / \mathrm{s}$ and that of PS, $U_{s}^{\mathrm{PS}}$, was $32.66 \pm 0.645 \mathrm{~km} / \mathrm{s}$.

The Al Hugoniot has been investigated over a wide range of pressures. Here, we used the SESAME model (table \#3717) (Ref. 21) of Al to determine polystyrene Hugoniot points. The $u_{p}^{\mathrm{Al}}$ and $P^{\mathrm{Al}}$ corresponding to the shock velocity described above were determined as $16.62 \mathrm{~km} / \mathrm{s}$ and $1.182 \mathrm{TPa}$, respectively. When the shock wave propagates through the interface between $\mathrm{Al}$ and PS, an unloading wave travels in the primary shocked $\mathrm{Al}$. The unloaded $\mathrm{Al}$ condition is given by the intersection of the unloading isentrope of $\mathrm{Al}$ and the Rayleigh line of PS; $P=\rho_{0}^{\mathrm{PS}} U_{s}^{\mathrm{PS}} u_{p}$ in the $P-u_{p}$ plane. The isentrope was also obtained from the SESAME table. Consequently, in shot 25368 , the particle velocity, pressure, and density in PS were $20.70 \pm 0.63 \mathrm{~km} / \mathrm{s}, 703 \pm 30 \mathrm{GPa}$, and $2.841 \pm 0.13 \mathrm{~g} / \mathrm{cm}^{3}$, respectively. The determination manner of these errors is described in the Appendix of Ref. 13. All obtained Hugoniot data are summarized in Table I.

The experimental data are plotted in Fig. 2. Open squares indicate present works. Gray circles are the results measured by Cauble et al. in indirect laser-driven experiment. ${ }^{9}$ Solid, dashed, and dot-dashed curves show the SESAME, ${ }^{21}$ QEOS, ${ }^{22}$ and Ree's theoretical model, ${ }^{23}$ respectively. Present results by the standard experimental technique are in full agreement with the previous work that used a completely different scheme, ${ }^{9}$ thus confirming the lower compressibility of polystyrene in this high-pressure region. In this experiment, preheating temperatures in $\mathrm{Al}$ and PS were lower than a detection limit $(\sim 0.9 \mathrm{eV})$ of the selfemission diagnostic. Moreover, from the results of reflectivity measurement, the temperature level was estimated as lower than $0.09 \mathrm{eV}^{25}$. This level of preheating cannot explain the lower compressibility of polystyrene in this pressure region. Indeed, even if we give an initial temperature of $1 \mathrm{eV}$, as preheating, to the PS SESAME model, the model does not match the data very well.

From these experimental data, we derived linear $U_{s}-u_{p}$ approximation relations, $U_{s}=c+s \cdot u_{p}$, based on the weighted least-squares method. The coefficients $c$ and $s$ for each experiment and the combined data set are listed in Table II. Accuracy of $u_{p}$ calculated from the "combined" relationship is approximately $9 \%$ in $50 \mathrm{~km} / \mathrm{s}$ shock velocity range and the $3 \%$ measurement error. In this case, the error of pressure 
TABLE I. Measured polystyrene Hugoniot.

\begin{tabular}{lcccc}
\hline \hline $\begin{array}{l}\text { Shot } \\
\text { No. }\end{array}$ & $\begin{array}{c}\text { Shock velocity } \\
(\mathrm{km} / \mathrm{s})\end{array}$ & $\begin{array}{c}\text { Particle velocity } \\
(\mathrm{km} / \mathrm{s})\end{array}$ & $\begin{array}{c}\text { Pressure } \\
(\mathrm{TPa})\end{array}$ & $\begin{array}{c}\text { Density } \\
\left(\mathrm{g} / \mathrm{cm}^{3}\right)\end{array}$ \\
\hline 25339 & $62.14 \pm 2.78$ & $41.06 \pm 2.95$ & $2.655 \pm 0.23$ & $3.067 \pm 0.37$ \\
25347 & $42.31 \pm 3.60$ & $27.79 \pm 3.29$ & $1.233 \pm 0.18$ & $3.030 \pm 0.56$ \\
25354 & $36.02 \pm 1.08$ & $22.19 \pm 0.86$ & $0.834 \pm 0.04$ & $2.710 \pm 0.16$ \\
25368 & $32.66 \pm 0.65$ & $20.70 \pm 0.63$ & $0.703 \pm 0.03$ & $2.841 \pm 0.13$ \\
26304 & $26.04 \pm 1.63$ & $16.31 \pm 1.42$ & $0.464 \pm 0.05$ & $2.783 \pm 0.37$ \\
26309 & $37.62 \pm 3.03$ & $24.62 \pm 2.59$ & $1.036 \pm 0.14$ & $3.010 \pm 0.52$ \\
26403 & $40.78 \pm 2.51$ & $25.84 \pm 2.08$ & $1.141 \pm 0.12$ & $2.839 \pm 0.35$ \\
26411 & $37.50 \pm 2.35$ & $23.38 \pm 2.11$ & $0.916 \pm 0.11$ & $2.763 \pm 0.38$ \\
\hline \hline
\end{tabular}

should be smaller than $10 \%$. These are not that bad despite the large errors of the coefficients: $(d c / c)$ and $(d s / s)$ $\sim 34.1 \%$ and $6.5 \%$, respectively. Here, the $u_{p}$ error $\left(d u_{p} / u_{p}\right)$ is given by

$\left(\frac{d u_{p}}{u_{p}}\right)=\sqrt{\left(\frac{U_{s}}{U_{s}-c}\right)^{2}\left(\frac{d U_{s}}{U_{s}}\right)^{2}+\left(\frac{c}{U_{s}-c}\right)^{2}\left(\frac{d c}{c}\right)^{2}+\left(\frac{d s}{s}\right)^{2}}$.

The factor of $c /\left(U_{s}-c\right)$ decreases the influence of the $c$ error.
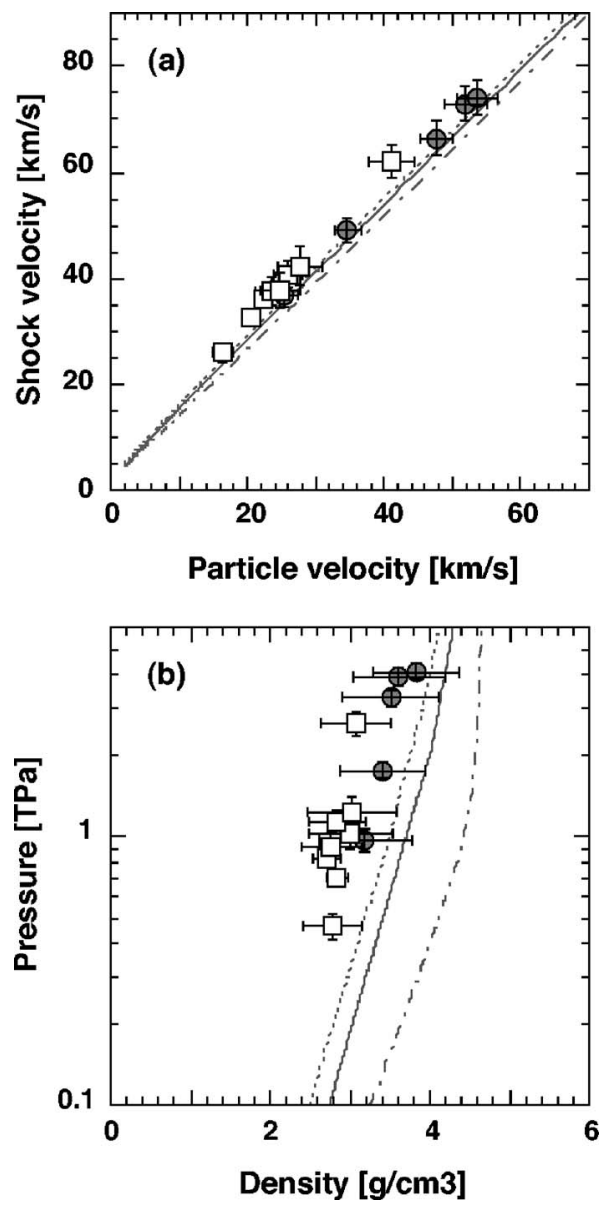

FIG. 2. Polystyrene Hugoniot data presented as (a) shock velocity vs particle velocity and (b) pressure vs density. The present data (open squares) and the previous data by Cauble et al. (Ref. 9, gray solid circles) are compared to the SESAME tabular EOS (Ref. 21, solid curve); QEOS (Ref. 22, dashed); and Ree's model (Ref. 23, dot-dashed).
For only present or Cauble coefficients, the accuracy of $u_{p}$ is worse than combined $(\sim 19 \%)$. By increasing data points, these coefficients would be more accurately defined. A reliable $U_{s}-u_{p}$ relation enables us to determine the EOS point in the $P-u_{p}$ plane by only measuring shock velocity for PS. In these high-pressure regions, as shocked PS will be conductive and the shock front strongly reflects probe lights, multiple VISAR diagnostics can therefore directly and accurately provide shock velocity. So, this means that unloading isentropes of EOS standard material in TPa pressure regions can be verified with VISARs and a double-step target consisting of the standard and PS. For the same reason, accurate Hugoniot measurements for low-density foam materials, which are of very low shock impedance, are interesting and valuable. ${ }^{24}$

In conclusion, we have presented EOS measurements for polystyrene based on the most orthodox experimental technique. The Hugoniot data from 0.7 to $2.7 \mathrm{TPa}$ were obtained, and the accuracies of $2.0 \%$ and $4.3 \%$ were achieved in shock velocity and pressure at their highest, respectively. The results were in very good agreement with previously published data obtained with completely different experimental techniques, suggesting that the polystyrene Hugoniot was stiffer than the Hugoniot predicted by a widely known EOS model.

\section{ACKNOWLEDGMENTS}

The authors gratefully acknowledge the valuable support for the experiments by the GXII technical crews and scientists at the ILE. In particular, the authors would like to thank K. Suzuki, S. Urushihara, H. Asahara, and N. Morio for operating the GXII, O. Maegawa for diagnostic support, and Y. Kimura, T. Norimatsu, and their group for target fabrications. The authors would like to thank S. Fujioka and T. Shiota for valuable experimental and analytical supports. This work

TABLE II. Coefficient $c$ and $s$ for the polystyrene Hugoniot, where $U_{s}=c$ $+s \cdot u_{p}$.

\begin{tabular}{lcc}
\hline \hline Data & $c$ & $s$ \\
\hline Present & 2.494 & 1.470 \\
Cauble et al. & 2.769 & 1.341 \\
Combined & 6.329 & 1.283 \\
\hline \hline
\end{tabular}


was performed under the auspices of the Japan Science and Technology Corporation (JST) by Osaka University under Contract No. A2-12308020.

${ }^{1}$ D. Saumon, G. Chabrier, and H. M. Van Horn, Astrophys. J., Suppl. Ser. 99, 713 (1995); W. J. Nellis, Planet. Space Sci. 48, 671 (2000).

${ }^{2}$ J. H. Nguyen and N. C. Holmes, Nature (London) 422, 339 (2004).

${ }^{3}$ S. W. Haan, S. M. Pollaine, J. D. Lindl, L. J. Suter, R. L. Berger, L. V. Powers, W. E. Alley, P. A. Amendt, J. A. Futerman, W. K. Levedahl, M. D. Rosen, D. P. Rowley, R. A. Sacks, A. I. Shestakov, G. L. Strobel, M. Tabak, S. V. Wever, G. B. Zimmerman, W. J. Krauser, D. C. Wilson, S. V. Coggeshall, D. B. Harris, N. M. Hoffman, and B. H. Wilde, Phys. Plasmas 2, 2480 (1995).

${ }^{4}$ J. D. Lindl, Phys. Plasmas 2, 3933 (1995).

${ }^{5}$ Y. B. Zel'dovich and Y. P. Raizer, Physics of Shock Waves and HighTemperature Hydrodynamic Phenomena (Academic, New York, 1966).

${ }^{6}$ M. Koenig, B. Faral, J. M. Boudenne, D. Batani, A. Benuzzi, S. Bossi, C. Remond, J. P. Perrine, M. Temporal, and S. Atzeni, Phys. Rev. Lett. 74, 2260 (1995).

${ }^{7}$ A. M. Evans, N. J. Freeman, P. Graham, C. J. Horsfield, S. D. Rothman, B. R. Thomas, and A. J. Tyrrell, Laser Part. Beams 14, 113 (1996).

${ }^{8}$ A. Benuzzi, Th. Löwer, M. Koenig, B. Faral, D. Batani, D. Beretta, C. Danson, and D. Pepler, Phys. Rev. E 54, 2162 (1996).

${ }^{9}$ R. Cauble, T. S. Perry, D. R. Bach, K. S. Budil, B. A. Hammel, G. W. Collins, D. M. Gold, J. Dunn, P. Celliers, L. B. Da Silva, M. E. Foord, R. J. Wallace, R. E. Stewart, and N. C. Woolsey, Phys. Rev. Lett. 80, 1248 (1998).

${ }^{10}$ S. D. Rothman, A. M. Evans, C. J. Horsfield, P. Graham, and B. R. Thomas, Phys. Plasmas 9, 1721 (2002).

${ }^{11}$ D. Batani, A. Morelli, M. Tomasini, A. Benuzzi-Mouniaix, F. Philippe, M. Koenig, B. Marchet, I. Masclet, M. Rabec, Ch. Reverdin, R. Cauble, P. Celliers, G. Collins, L. Da Silva, T. Hall, M. Moret, B. Sacchi, P. Baclet, and B. Cathala, Phys. Rev. Lett. 88, 235502 (2002).

${ }^{12}$ D. Batani, F. Strati, H. Stabile, M. Tomasini, G. Lucchini, A. Ravasio, M. Koenig, A. Benuzzi-Mounaix, H. Nishimura, Y. Ochi, J. Ullschmied, J. Skala, B. Kralikova, M. Pfeifer, Ch. Kadlec, T. Mocek, A.
Präg, T. Hall, P. Milani, E. Barborini, and P. Piseri, Phys. Rev. Lett. 92, 065503 (2004)

${ }^{13}$ N. Ozaki, K. A. Tanaka, T. Ono, K. Shigemori, M. Nakai, H. Azechi, T. Yamanaka, K. Wakabayashi, M. Yoshida, H. Nagao, and K. Kondo, Phys. Plasmas 11, 1600 (2004).

${ }^{14}$ N. Miyanaga, M. Nakatsuka, H. Azechi, H. Shiraga, T. Kanabe, H. Asahara, H. Daido, H. Fujita, and K. Fujita, in Proceedings of the 18th International Conference on Fusion Energy (IAEA, Sorrento, Italy, 2001), IAEA-CN-77.

${ }^{15} \mathrm{C}$. Yamanaka, in Proceedings of the Inertial Fusion Sciences and Applications 99, Bordeaux, 1999, edited by C. Labaune, W. J. Hogan, and K. A. Tanaka (Elsevier, Paris, 2000), p. 19.

${ }^{16}$ S. Skupsky, R. W. Short, T. Kessler, R. S. Craxton, S. Letzring, and J. M. Soures, J. Appl. Phys. 66, 3456 (1989).

${ }^{17}$ S. N. Dixit, M. D. Feit, M. D. Perry, and H. T. Powell, Opt. Lett. 21, 1715 (1996).

${ }^{18}$ T. Kadono, M. Yoshida, E. Takahashi, I. Matsushima, Y. Owadano, N. Ozaki, K. Fujita, M. Nakano, K. A. Tanaka, H. Takenaka, and K. Kondo, J. Appl. Phys. 88, 2943 (2000).

${ }^{19}$ K. Nagai, T. Norimatsu, T. Yamanaka, T. Nishibe, N. Ozaki, K. Takamatsu, T. Ono, M. Nakano, and K. A. Tanaka, Jpn. J. Appl. Phys., Part 2 41, L1184 (2002).

${ }^{20}$ K. Takamatsu, N. Ozaki, K. A. Tanaka, T. Ono, K. Nagai, M. Nakai, T. Watari, A. Sunahara, M. Nakano, T. Kataoka, H. Takenaka, M. Yoshida, K. Kondo, and T. Yamanaka, Phys. Rev. E 67, 056406 (2003).

${ }^{21}$ SESAME, the LANL equation-of-state database, Los Alamos National Laboratory, LA-UR-92-3407 (1992). Copies may be ordered from the National Technical Information Service, Springfield, VA 22161.

${ }^{22}$ R. M. More, K. H. Warren, D. A. Young, and G. B. Zimmerman, Phys. Fluids 31, 3059 (1988).

${ }^{23}$ F. H. Ree, Lawrence Livermore National Laboratory Report No. UCRL51885, 1975.

${ }^{24}$ M. Koenig, A. Benuzzi, F. Philippe, D. Batani, T. Hall, N. Grandjouan, and W. Nazarov, Phys. Plasmas 6, 3296 (1999).

${ }^{25}$ A. Benuzzi, M. Koenig, B. Faral, J. Krishnan, F. Pisani, D. Batani, S. Bossi, D. Beretta, T. Hall, S. Ellwi, S. Höller, J. Honrubia, and N. Grandjouan, Phys. Plasmas 5, 1 (1998). 